\title{
QUALITY BY DESIGN BASED DEVELOPMENT OF ETRAVIRINE SELF MICRO EMULSIFYING DRUG DELIVERY SYSTEM
}

\author{
KAVITHA A. N. ${ }^{*}{ }^{*}$, JANAKIRAMAN K. ${ }^{2}$, RAMAN DANG ${ }^{3}$
}

1Department of Pharmaceutics, Krupanidhi College of Pharmacy, Bengaluru 560035, Karnataka, India, ${ }^{2}$ Department of Pharmacy, Faculty of Engineering and Technology, Annamalai University, Tamil Nadu, India, 3Principal, KLE College of Pharmacy, Bengaluru, Karnataka, India Email: kavithareddykcp@gmail.com

Received: 13 Dec 2020, Revised and Accepted: 03 Mar 2021

\section{ABSTRACT}

Objective: The main objective of the present research work was to develop systematically the Self Micro Emulsifying Drug Delivery system of BCS Class IV drug in a Quality by Design framework.

Methods: The quality by design-based formulation development proceeds with defining the Quality Target Product Profile and Critical Quality Attributes of dosage form with appropriate justification for the same. The statistical Mixture design was used for the development of the formulation. The independent variables selected for the design were Oleic acid, Labrasol and PEG 6000, whereas droplet size (nm), emulsification time (sec), \% drug loading and \% drug release at 15 min were considered as the potential quality attributes of the Self Micro Emulsifying System. The eight different batches of Etravirine-Self Micro Emulsifying systems (ETV-SMEDDS) were prepared and checked for the Critical Quality Attributes. The simultaneous optimization of the formulation was done by the global desirability approach.

Results: The characterization report obtained for all the different batches of formulation was analyzed statistically by fitting into regression models. The statistically significant models determined for droplet size (nm) $\left(\mathrm{R}^{2}=0.96\right.$ and $\left.\mathrm{p}-0.1022\right)$, emulsification time (sec) $\left(\mathrm{R}^{2}=0.99\right.$ and $\left.\mathrm{p}-0.0267\right)$, \% drug loading $\left(\mathrm{R}^{2}=0.93\right.$ and $\left.\mathrm{p}-0.1667\right)$ and \% drug release at $15 \mathrm{~min}\left(\mathrm{R}^{2}=0.96\right.$ and $\left.\mathrm{p}-0.0911\right)$ and were statistically significant. The maximal global desirability value obtained was 0.9415 and the value indicates, the selected factors and responses have a good correlation and are significant enough for optimization and prediction of best formulation.

Conclusion: The QbD approach utilized during the development of ETV-SMEEDS facilitated the identification of Critical Material Attributes and their significant impact on the Critical Quality Attributes of SMEDDS. The concept of building quality into product through the QbD application was utilized successfully in the formulation development.

Keywords: Bioavailability, Etravirine, Risk Assessment, SMEDDS, QbD

(C) 2021 The Authors. Published by Innovare Academic Sciences Pvt Ltd. This is an open access article under the CC BY license (https://creativecommons.org/licenses/by/4.0/) DOI: https://dx.doi.org/10.22159/ijap.2021v13i3.40488. Journal homepage: https://innovareacademics.in/journals/index.php/ijap

\section{INTRODUCTION}

Pharmaceutical industry is the highly regulated industry and it is controlled by the authoritative regulatory bodies. The regulatory agencies emphasizes on the quality of pharmaceutical products. Quality can be planned and majority of the quality deficiency occur in the way the process is planned and developed [1]. The concept of Quality by Design and its application in the product development was introduced by the quality expert Joseph Moses Juran. The principles of QbD have been used in every industry to improve quality of the product and process [2,3].

Among the second-generation Non-Nucleoside Reverse Transcriptase Inhibitors (NNRTIs), Etravirine is the first drug and has been recently used for the treatment of HIV infection. Etravirine is used more extensively in comparison to other available first generation NNRTIs due to its activity against NNRTI-resistant HIV-1 [4]. The drug shows its action by binding directly to the reverse transcriptase of HIV-1 and consequently blocks the activity of DNAdependent and RNA-dependent polymerase [5]. Etravirine belongs to Biopharmaceutical Classification System (BCS) IV and the limited therapeutic potential is due to its low solubility and permeability characteristics. There is a requirement for the development of more bioavailable formulation of ETV to facilitate better clinical outcomes. Self-Micro Emulsifying Drug Delivery (SMEDDS) system is the variant of a lipid-based formulation used for the development of poorly water-soluble drugs. SMEDDS comprises oil, surfactant and cosurfactant, sometimes cosolvent [6]. The in vivo emulsification of SMEDDS takes place once it comes in contact with the GI fluids under the mild agitation provided by the GI motility. SMEDDS finds its potential application in the enhancement of oral bioavailability of poorly water-soluble drugs belonging to BCS Class II and IV [7, 8]. In the present study, the concept of building quality into product through the $\mathrm{QbD}$ application was utilized in the development of
Etravirine Self Micro Emulsifying Drug Delivery System (ETVSMEDDS).

\section{MATERIALS AND METHODS}

\section{Materials}

Etravirine was received as gift sample form Hetero Pvt Ltd, Hyderabad, India. Labrasol, Maisine CC, Labrafil M 1944 CS, Capryol 90 and Transcutol HP were obtained as gift samples from Gattefosse, Saint-Priest Cedex, France. Span 80, Span 20, Oleic acid and PEG 6000 were purchased from Sigma-Aldrich, Germany. All other chemicals used in the present study were of analytical grade.

\section{Methods}

Defining the quality target product profile (QTPP) and critical quality attributes (CQA)

The product development through QbD approach advocates on defining the QTPP and it is one of the prerequisites to deliver therapeutic benefits as per label claim. The QTPP for liquid SMEDDS was defined and it is based on the patient-centric (emulsification time, globule size, drug release) and product centric (zeta potential) quality attributes of the drug product. The CQAs were identified from QTPP and they were interlinked to give the desired quality, safety and efficacy to the product, which shows prominent changes when QTPP are altered $[9,10]$. The QTPP and CQAs were listed in the table 1 and 2 , respectively.

\section{Risk assessment}

Risk assessment is a combined effort of identifying and evaluating the factors that may have an impact on the product's CQAs. The risk assessment tools help in identifying and mitigating the risks and prioritize the risk as high, medium or low based on the impact level. 
The two qualitative tools used in the present study were Fishbone diagram and Risk Estimation Matrix table. Fishbone diagram (fig. 1) was constructed by using JMP Ver 13.2 software. Fishbone diagram depicts the cause and sub causes affecting the CQAs and risk assessment matrix helps in categorizing the risk. The table 3 represents the risk estimation matrix for ETV-SMEDDS

Table 1: Quality target product profile of ETV-SMEDDS

\begin{tabular}{|c|c|c|c|}
\hline \multicolumn{2}{|c|}{ QTPP elements } & Target & Justification \\
\hline \multicolumn{2}{|c|}{ Dosage type } & Lipid-based formulation & Enhancement of Bioavailability of poorly water-soluble drugs \\
\hline \multicolumn{2}{|c|}{ Dosage form } & Capsule & Ease of administration \\
\hline \multicolumn{2}{|c|}{ Dosage strength } & $50 \mathrm{mg}$ & Required to show the therapeutic action at the target site \\
\hline \multicolumn{2}{|c|}{ Route of administration } & Oral & Most convenient route for AIDS patients (Patient acceptability) \\
\hline \multicolumn{2}{|c|}{ Packaging } & Alu-Alu Blister & Maximum protection and gives a prolonged shelf life \\
\hline Product & Physical attributes & \multicolumn{2}{|c|}{ Formulation must meet the compendial quality standards } \\
\hline Quality & Droplet size & & \\
\hline \multirow[t]{6}{*}{ Attributes } & Transmittance & & \\
\hline & Poly dispersibility index & & \\
\hline & Zeta potential & & \\
\hline & Emulsification efficiency & & \\
\hline & Drug content & & \\
\hline & Drug release & & \\
\hline \multicolumn{2}{|l|}{ Stability } & $\begin{array}{l}\text { As per the conditions of ICH } \\
\text { Q1B Long term stability studies }\end{array}$ & $\begin{array}{l}\text { To maintain the therapeutic level of the drug during the shelf life } \\
\text { period }\end{array}$ \\
\hline \multicolumn{2}{|c|}{ Pharmacokinetic parameters } & Tmax, Cmax, AUC & $\begin{array}{l}\text { Maximum drug levels in systemic circulation helps to improve the } \\
\text { therapeutic efficiency }\end{array}$ \\
\hline
\end{tabular}

Table 2: Critical quality attributes of ETV-SMEDDS

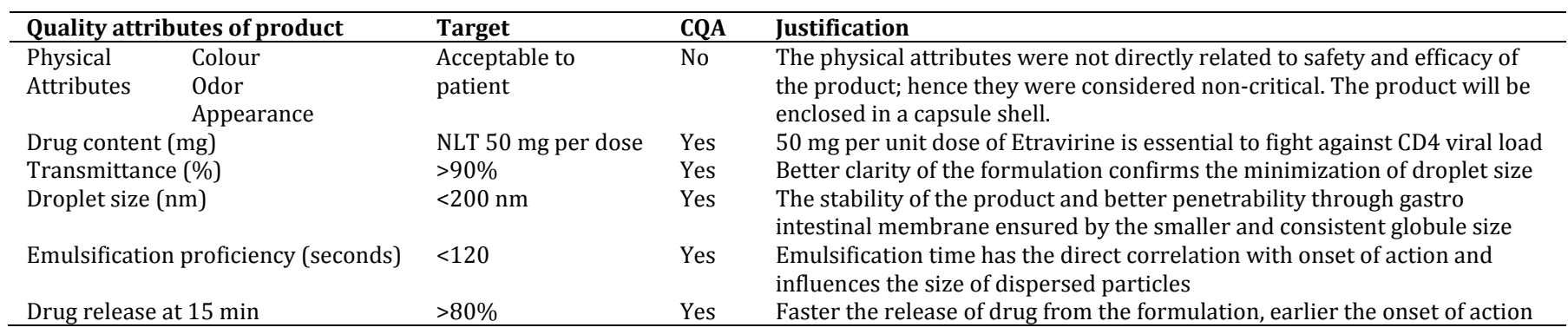

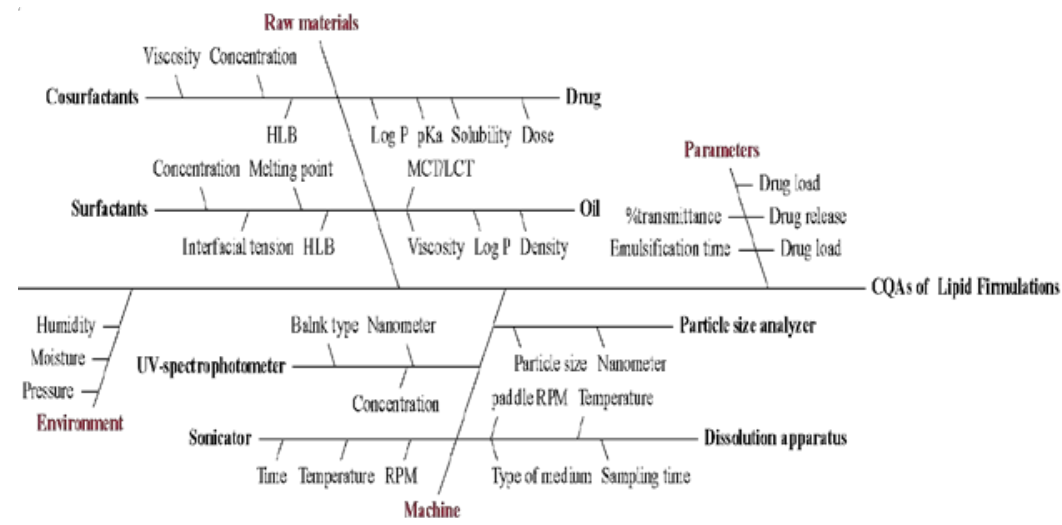

Fig. 1: Fishbone diagram depicting causes and sub causes affecting ETV-SMEDDS quality attributes

Table 3: Risk estimation matrix table for ETV-SMEDDS

\begin{tabular}{|c|c|c|c|c|c|c|c|c|}
\hline & & \multicolumn{7}{|c|}{ Critical quality attributes } \\
\hline & & $\begin{array}{l}\text { Droplet } \\
\text { size }\end{array}$ & $\begin{array}{l}\text { Transmit } \\
\text { tance }\end{array}$ & PDI & $\begin{array}{l}\text { Zeta } \\
\text { potential }\end{array}$ & $\begin{array}{l}\text { Emulsification } \\
\text { time }\end{array}$ & $\begin{array}{l}\text { Drug } \\
\text { content }\end{array}$ & $\begin{array}{l}\text { Drug } \\
\text { release }\end{array}$ \\
\hline Material & Drug & Low & Low & Low & Low & Low & High & Medium \\
\hline \multirow[t]{3}{*}{ Attributes } & Oleic acid & High & High & High & High & High & High & High \\
\hline & Labrasol & High & High & High & High & High & High & High \\
\hline & PEG 6000 & High & High & High & High & High & High & High \\
\hline Process & Stirring Time & High & Medium & Low & Low & Low & Low & Low \\
\hline \multirow[t]{3}{*}{ Attributes } & Stirring Speed & Medium & Medium & Low & Low & Low & Low & Low \\
\hline & Stirring Temperature & Medium & Medium & Medium & Medium & Medium & Low & Low \\
\hline & Sonication & High & Medium & Medium & Medium & Medium & Low & Low \\
\hline
\end{tabular}




\section{Solubility study}

The solubility of Etravirine in various oils, surfactants and cosurfactants was checked. To perform the solubility study, the excess amount of drug was added to each excipient $(2 \mathrm{ml})$ and vortexed for $48 \mathrm{~h}$ to maintain the equilibrium. The samples were centrifuged at $3000 \mathrm{rpm}$ for $15 \mathrm{~min}$. The supernatant liquid was filtered through a $0.45 \mu \mathrm{m}$ Millipore ${ }^{\circledR}$ filter and suitably diluted with a solvent mixture of Methanol and Water (1:9) and analyzed at 310 $\mathrm{nm}$ using UV Spectrophotometer (UV 1800 Shimadzu). Studies were carried out in triplicates to assure accuracy [11]

\section{Construction of pseudo ternary phase diagram}

The objective of constructing Pseudo ternary phase diagrams was to check the concentration ranges of SMEDDS components which could give nano or microemulsion regions. The phase diagrams were constructed by using Prosim ${ }^{\circledR}$ Ternary plot software. The oil (Oleic acid), surfactant (Labrasol) and cosurfactant (PEG 6000) were selected based on the solubility studies. Surfactant and Cosurfactant (Smix) were prepared in different ratios (1:1, 2:1 and 3:1). A varying proportion of Oil and Smix were mixed $(1: 9,2: 8,3: 7,4: 6,5: 5,6: 4$,
7:3, 8:2, and 9:1 respectively) and homogenized by using a vortex mixer. The double-distilled water was added to the mixture at an increment of $5 \%$ in the range of 5 to $95 \%$ of total volume, vortexed and allowed to equilibrate [12].

\section{Design of experiments}

Design of Experiments (DoE) deals with planning, analyzing and interpreting the factors that control the responses. Mixture design was chosen from the classical category of DoE software based on the convenience and minimal number of runs given by design [13]. For this study, JMP $₫$ Ver 13.2 software was used to create the formulation plan after choosing the appropriate oil, surfactant and cosurfactant. The mixture design was used in the development of SMEDDS formulation because the factors are the proportion of blend. The independent variables (material attributes) considered in the design were Oleic acid, Labrasol and PEG 6000 (table 4). The droplet size (nm), emulsification time (sec), \% drug loading and \% drug release at $15 \mathrm{~min}$ were the dependent variables chosen for the study (table 4). Through the mixture design total of eight different batches of SMEDDS formulations were obtained and subjected for checking the CQAs.

Table 4: Independent and dependent variables and their limits in mixture design

\begin{tabular}{llll}
\hline Independent variables & & & Lower value \\
\hline Factors & Role & 0.1 & Higher value \\
Oleic Acid & Mixture & 0.577 & 0.23 \\
Labrasol & Mixture & 0.193 & 0.675 \\
PEG 6000 & Mixture & & 0.225 \\
Dependent variables & & Lower limit & Higher limit \\
Variables & Goal & 100 & 500 \\
Droplet Size in nm & Minimize & 20 & 60 \\
Emulsification time in Sec & Minimize & 90 & 100 \\
\% Drug loading & Maximize & 70 & 100 \\
\hline
\end{tabular}

\section{Preparation of liquid SEDDS formulation}

Eight different batches of ETV-SMEDDS were prepared as per the mixture design. The formulations were developed by dissolving 50 $\mathrm{mg}$ of drug in the mixture of Oleic acid, Labrasol and PEG 6000 and followed by heating at $40{ }^{\circ} \mathrm{C}$ in a water bath. The same mixture was then vortexed until it became clear and transparent. The prepared formulations were stored in ambient temperature until use [14].

\section{Evaluation of liquid SMEDDS}

\section{Droplet size analysis}

The droplet size of the prepared ETV-SMEDDS was checked by diluting the sample with double distilled water at the ratio of 1:100 $(\mathrm{v} / \mathrm{v})$. The mean droplet size and Polydispersity index (PDI) was measured in triplicates by photon correlation spectroscopy using Malvern Zetasizer Nano-ZS (Malvern Instruments, United Kingdom) $[15,16]$.

\section{Emulsification time}

The self-emulsification time was determined by using USP Type II dissolution apparatus (LABINDIA, DS 8000, MUMBAI). $1 \mathrm{ml}$ of the formulation was added dropwise into a $500 \mathrm{ml}$ of double-distilled water, maintained at the temperature of $37 \pm 0.5{ }^{\circ} \mathrm{C}$, under mild agitation of paddle $(50 \mathrm{rpm})$. Each formulation is observed visually for clarity, homogenization and for precipitation of drug. The time taken by each formulation to form a clear emulsion was noted in seconds [17].

\section{Drug loading}

The pre-concentrated SMEDDS equivalent to $50 \mathrm{mg}$ of Etravine was taken and the drug was extracted by using a small quantity of methanol. The volume was made up to $100 \mathrm{ml}$ with double distilled water. From the stock solution, $0.1 \mathrm{ml}$ was withdrawn and diluted up to $10 \mathrm{ml}$ with double distilled water. The resultant solution absorbance was measured at $310 \mathrm{~nm}$ by UV-Visible
Spectrophotometer (UV 1800, Shimadzu). The drug content measurements were carried out in triplicates [18].

\section{In vitro drug release studies}

In vitro drug release studies were executed in the phosphate buffer (pH 6.8) with $2 \%$ Tween 20 using USP-II basket type dissolution apparatus. The temperature of the medium was maintained 37 ${ }^{\circ} \mathrm{C} \pm 0.5$ and rpm was set to 50 . The SMEDDS formulation equivalent to $50 \mathrm{mg}$ of drug was filled into the hard gelatin capsules. The capsules were placed inside the jars with the help of stainless steel sinkers to avoid buoyancy. Samples were withdrawn from the dissolution jars at the time intervals of 5, 10, 15, 30, 45 and 60 min and further diluted with phosphate buffer and analyzed by UVVisible Spectrometer (UV 1800, Shimadzu) at $310 \mathrm{~nm}$ [19].

\section{Model evaluation and validation}

Model evaluation was carried out by incorporating the various responses obtained for all the eighth formulations into the design. The data of Droplet size (nm), Emulsification time (sec) \% Drug loading and \% Drug release at 15 min were statistically analyzed by various multiple regression models. The validation of the design was carried out with the help of Ternary Mixture Profiler. The profilers consist of ternary plot, factor settings with the controls and response settings and its controls. The verification batch was prepared as per the Ternary Mixture Profiler and checked for the predicted CQAs. The lack of differences in the variance between observed and predicted responses indicates the goodness of fit.

\section{Optimization of formulation}

The simultaneous optimization of the formulation was done by using the Prediction profiler. Prediction Profiler gives a visual way to see how changing one factor setting impacts the response as well as impacts the other factors in the model. The global desirability function obtained for the model was taken as a key component for optimization. The overall desirability value shows on a scale of zero 
to one. Optimized formulation (OF) was prepared based on the prediction profiler and was evaluated for the responses. The zeta potential of the optimized formulation was measured by using Malvern Zetasizer Nano-ZS.

\section{RESULTS AND DISCUSSION}

Although several works have reported the formulation of ETV SEDDS by OFAT approach either to enhance bioavailability or to attain other formulation goals [20]. A rigorous development of ETVSMEDDS by QbD approach was not present. Developing sparsely bioavailble drugs in a $\mathrm{QbD}$ approach affords the researcher to get sophisticated understanding of risk associated with the formulation and methods to overcome it. The OFAT method reported by earlier researchers might not be tenable for replication; however, this approach adopted by us is rigorous in its approach to development following the $\mathrm{QbD}$ paradigm and establishes the likely multivariate relationship for the factors and responses considered for the formulation and its likely outcome in statistically tenable manner.

\section{Risk assessment}

The dosage form development under QbD framework involves material evaluation as well as process attributes which have a greater impact on the quality of the drug. The two qualitative risk assessment tools which were used in the present study were Ishikawa diagram and Risk Estimation matrix table. Ishikawa diagram is also called Cause-and-effect/Fishbone diagram, by using this diagram, we identified all the contributing root causes likely to be causing problems in ETV-SMEDDS. In the risk assessment matrix table, each factor was assigned with a risk grade of low, medium or high as per priority and the factors with high risk were selected for the design of the experiment in order to arrive at design space.

\section{Solubility study}

The solubility of Etravirine in various oils, surfactants and cosurfactants was checked and the report obtained is presented in fig. 2. The highest solubility of a drug in any lipid would augment its drug loading capacity. Accordingly, on the basis of maximum solubility, Oleic acid $(31.2 \pm 1.9 \mathrm{mg} / \mathrm{ml})$ was selected as oil phase in the formulation of SMEDDS and it was also reported that oleic acid enhances the intestinal absorption of the drug, which leads to the lymphatic transport of the drug. Labrasol $(74 \mathrm{mg} / \mathrm{ml})$ was selected as surfactant based on both emulsification efficiency and solubility of Etravirine. Co-surfactants increase the interfacial fluidity by penetrating into the surfactant film creating void space among surfactant molecules. Among various cosurfactants, PEG 6000 $(52.4 \pm 1.5 \mathrm{mg} / \mathrm{ml})$ was selected for the formulation development.

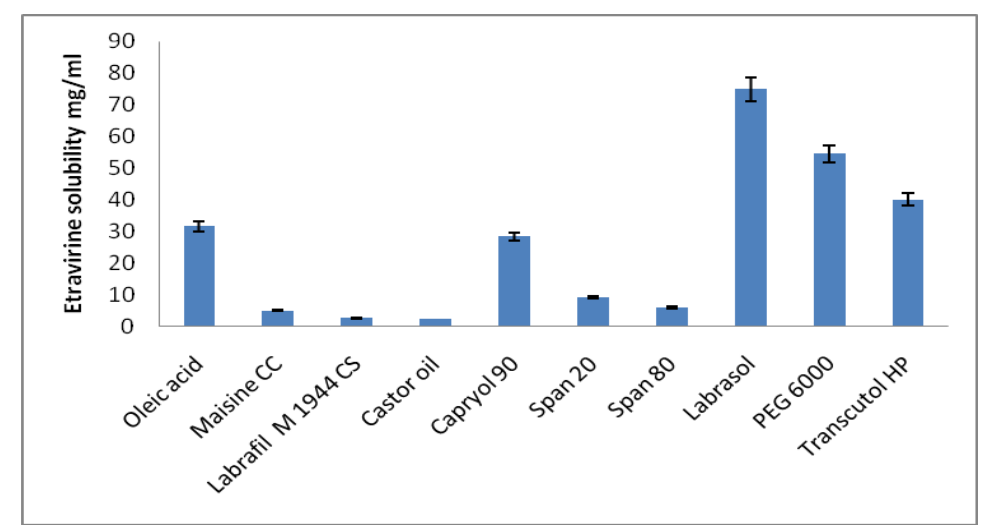

Fig. 2: Solubility study report (mean $\pm S D, n=3$ )

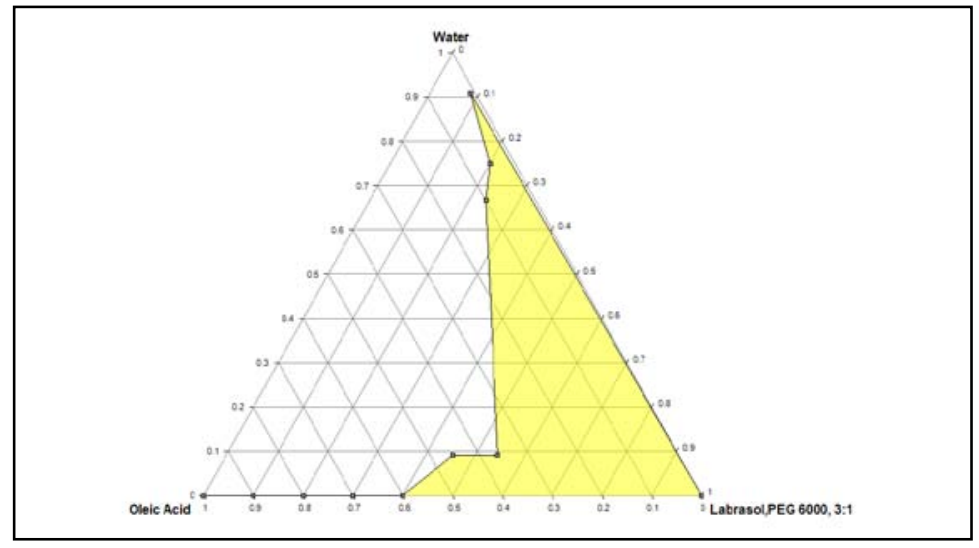

Fig. 3: Pseudo ternary phase diagram

\section{Pseudo ternary phase diagram}

The main objective is to study the relationship between the phase behavior relative to the composition, which helps in determining the concentration range of components for the formation of an emulsion. In order to apply DOE for the formulation, it was necessary to identify the highest self-emulsifying region from ternary phase diagrams. Amongst the different combinations, Oleic acid with Labrasol and PEG 6000 at the Smix ratio of 3:1 was able to give a maximal region for stable nano/microemulsion.

\section{Design of experiment}

The application of DOE tools is important in achieving quality within the product with minimal experimentation. Hence, Mixture design was employed for 3 factors (oil, surfactant and cosurfactant) and 4 responses (particle size, emulsification time, drug loading and \% drug release) and the extreme values drawn from the phase diagram was specified in the design along with the required target values for the responses. Within a few steps of computing the formulation trials initially, an optimal design was selected under mixture design 
for which randomized run order of 8 default runs was generated by the software. The characterization report obtained for the prepared formulations was integrated to the design matrix in order to plot the known responses and also mainly to predict the not formulated and non-evaluated intermediate combinations of the excipients and to predict a continuous response curve which was later used in optimizing and validating the best formulations with best outcomes.

\section{Characterization of formulations}

Droplet size distribution is one of the stability-indicating characteristics of the emulsion. The mean droplet size obtained for all eight formulations was in the range of 257.1 to $667.9 \mathrm{~nm}$. Smaller the droplet size, better is the absorption of the drug and enhances the bioavailability of drug product. The in vitro assessment of selfemulsification was carried out to ensure, the SMEDDS on contact with GI fluids will undergo emulsification spontaneously. The emulsification time required for all the formulations was less than 1 min indicates the minimum requirement of free energy for self emulsification. The $\%$ drug content of all the formulations was found to be satisfactory (93.0 to $99.8 \%$ ). The in vitro drug release studies showed all formulations released more than $74 \%$ of the drug within $15 \mathrm{~min}$. The formulation EFM8 showed the highest drug release of $91 \%$, whereas EFM 7 shows the least \% drug release of $74 \%$. The slowdown of drug release may be attributed to reduced diffusion of the drug through the lamellar surfactant/cosurfactant layers, which also increases the microenvironment viscosity.

Table 5: Mixture design formulations and observed responses

\begin{tabular}{lllllll}
\hline Formulation & $\begin{array}{l}\text { Oleic } \\
\text { acid }\end{array}$ & Labrasol & PEG 600 & Droplet size nm & $\begin{array}{l}\text { Emulsification } \\
\text { time sec }\end{array}$ & $\begin{array}{l}\text { \% Drug loading } \\
\text { \% Drug release at } \\
\text { 15 min }\end{array}$ \\
\hline EFM1 & 0.116 & 0.675 & 0.209 & $297.84 \pm 2.35$ & $26.0 \pm 1.0$ & $99.19 \pm 0.21$ \\
EFM2 & 0.181 & 0.626 & 0.193 & $310.75 \pm 5.87$ & $30.33 \pm 0.58$ & $98.90 \pm 0.30$ \\
EFM3 & 0.198 & 0.577 & 0.225 & $380.55 \pm 5.39$ & $30.33 \pm 0.58$ & $98.11 \pm 0.10$ \\
EFM4 & 0.132 & 0.675 & 0.193 & $287.28 \pm 1.67$ & $27.33 \pm 0.58$ & $98.95 \pm 0.76$ \\
EFM5 & 0.214 & 0.577 & 0.209 & $589.26 \pm 3.48$ & $35.33 \pm 0.58$ & $94.18 \pm 0.65$ \\
EFM6 & 0.149 & 0.626 & 0.225 & $293.48 \pm 4.92$ & $26.0 \pm 0.0$ & $99.04 \pm 0.56$ \\
EFM7 & 0.23 & 0.577 & 0.193 & $667.74 \pm 9.69$ & $40.33 \pm 0.58$ & $93.34 \pm 0.42$ \\
EFM8 & 0.1 & 0.675 & 0.225 & $257.16 \pm 2.45$ & $24.0 \pm 1.0$ & $75.97 \pm 0.62$ \\
\hline
\end{tabular}

*Data expressed as mean \pm SD $(n=3)$

\section{Evaluation of model}

The data obtained for all eight formulation batches were integrated in the design to check the model fit. The data obtained was analyzed statistically by fitting multiple regression models with the intercept set to zero. The statistically significant models determined for droplet size $(\mathrm{nm})\left(\mathrm{R}^{2}=0.96\right.$ and $\left.\mathrm{p}-0.1022\right)$, emulsification time $(\mathrm{sec})\left(\mathrm{R}^{2}=0.99\right.$ and $\mathrm{p}-0.0267), \%$ drug loading $\left(\mathrm{R}^{2}=0.93\right.$ and $\left.\mathrm{p}-0.1667\right)$ and $\%$ drug release at $15 \mathrm{~min}\left(\mathrm{R}^{2}=0.96\right.$ and $\left.\mathrm{p}-0.0911\right)$ were statistically significant. The effects test report and leverage plots obtained for all the individual responses considered in the design are presented in table 6 and fig. 4 , respectively. The effects test report obtained for the droplet size indicates Oleic acid (p-0.0069) has a significant effect on the model.
The emulsification time depends on both Oleic acid (p-0.0006) and Labrasol (p-0.0072). The \% drug loading is influenced by Oleic acid ( $\mathrm{p}$ $0.0002)$ and Labrasol (p-0.0008), and similarly, the $\%$ drug release also depends on Oleic acid (p-0.0010)and Labrasol (p-0.0038).

The effects summary of the whole model was used to investigate the effect of independent variables on dependent variables. In the graph, the length of each bar shows the effect of variables and the magnitude of the effect on the quality attributes. In the effects summary table the bar presenting Oleic acid and Labrasol crosses the blue vertical line indicating the significance. Hence, the material attributes like Oleic acid and Labrasol considered in the design were having a significant influence on the responses.
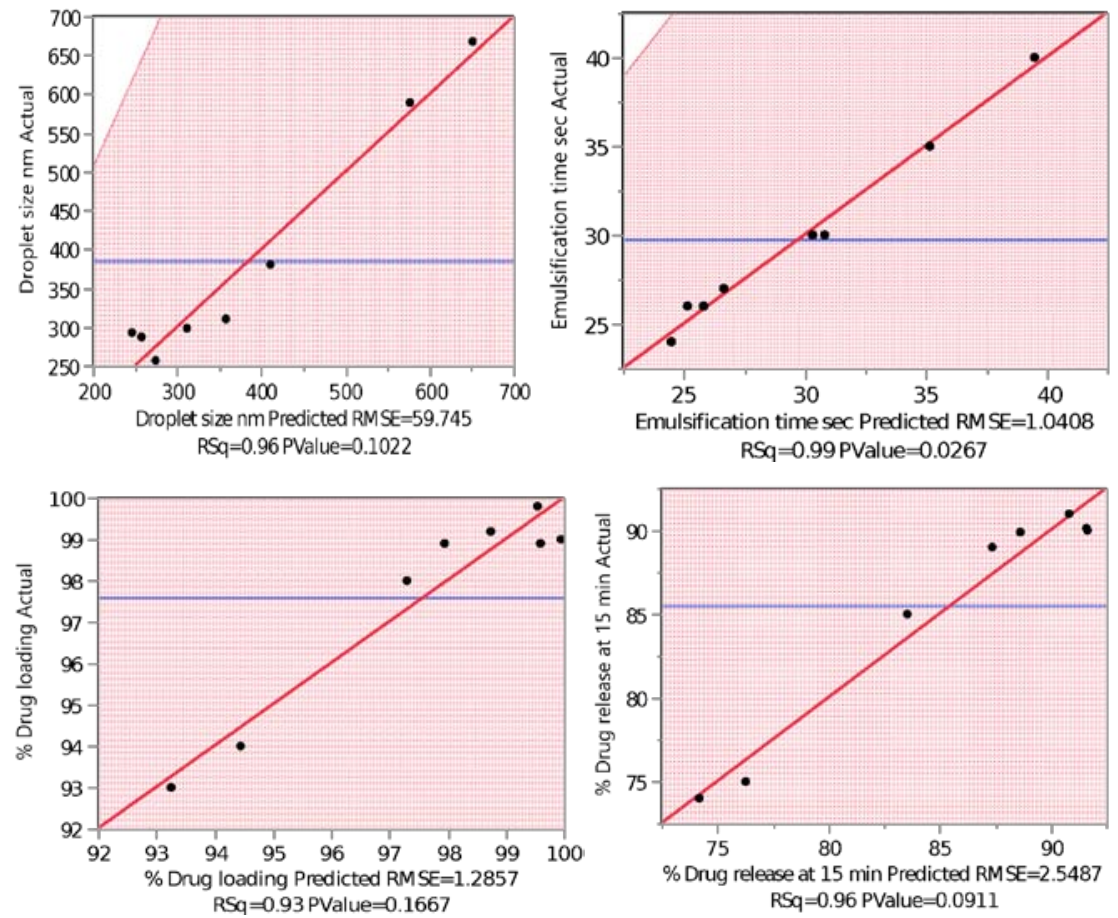

Fig. 4: Actual Vs predicted plots for dependent variables 
Kavitha et al.

Table 6: Effects test report for dependent variable

\begin{tabular}{lllll}
\hline Source & Prob>F & & & \\
\cline { 2 - 5 } & Droplet size & Emulsification time & \% Drug load & \% Drug release at 15 min \\
\hline (Oleic acid-0.1)/0.13 & $0.0069^{*}$ & $0.0006^{*}$ & $0.0002^{*}$ & $0.0010^{*}$ \\
(Labrasol-0.577)/0.13 & 0.1492 & $0.0072^{*}$ & $0.0008^{*}$ & $0.0038^{*}$ \\
(PEG 6000-0.193)/0.13 & 0.4236 & 0.8434 & 0.1147 & 0.1627 \\
Oleic acid*Labrasol & 0.2037 & 0.1299 & 0.3043 & 0.1804 \\
Oleic acid*PEG 6000 & 0.4701 & 0.8075 & 0.5337 & 0.3622 \\
Labrasol*PEG 6000 & 0.4106 & 0.6039 & 0.4843 & 0.3353 \\
\hline
\end{tabular}
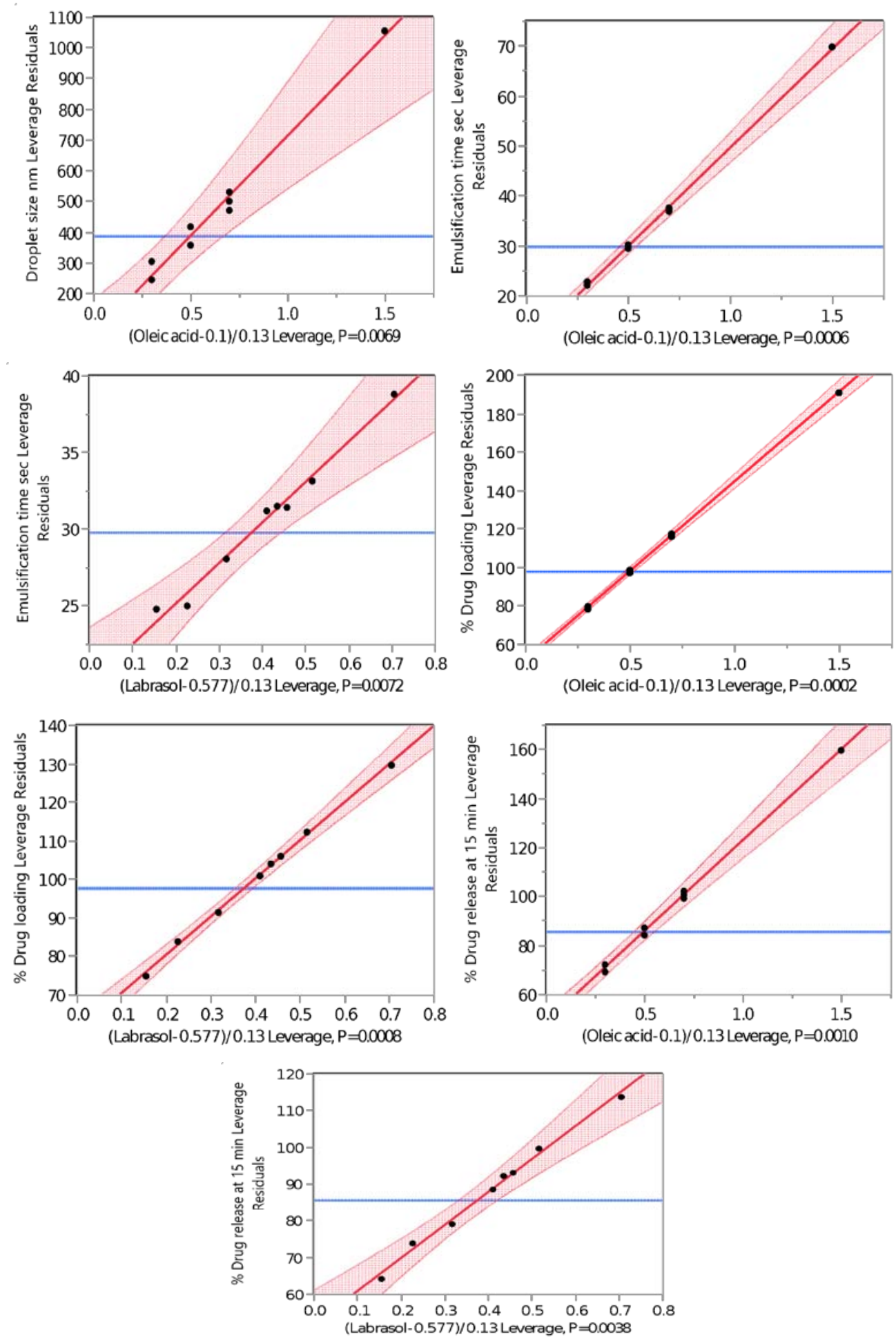

Fig. 5: Leverage plots for dependent variables 


\begin{tabular}{lll:l}
\hline Source & Log worth & P value \\
\hline (Oleic acid-0.1)/0.13 & 3.800 & \\
(Labrasol-0.577)/0.13 & 3.104 & \\
(PEG 6000-0.193)/0.13 & 0.940 & 0.00016 \\
Oleic acid*Labrasol & 0.886 & 0.0079 \\
Labrasol*PEG 6000 & 0.475 & 0.11474 \\
Oleic acid*PEG 6000 & 0.441 & 0.33526 \\
\hline
\end{tabular}

Fig. 6: Effects summary report

Table 7: Summary of the model fit

\begin{tabular}{|c|c|c|c|c|}
\hline Statistical parameters & Droplet size (nm) & Emulsification time (sec) & \% Drug loading & \% Drug release at $15 \mathrm{~min}$ \\
\hline R Square & 0.957788 & 0.989247 & 0.929641 & 0.962495 \\
\hline R Square Adj & 0.852257 & 0.962366 & 0.753744 & 0.868733 \\
\hline Root Mean Square Error & 59.74549 & 1.040833 & 1.285697 & 2.548653 \\
\hline Mean of Response & 385.575 & 29.75 & 97.59875 & 85.505 \\
\hline Observations (or Sum Wgts) & 8 & 8 & 8 & 8 \\
\hline
\end{tabular}

\section{Design verification}

The design validation was carried out by conducting the experimental batch as per the Ternary mixture profiler (fig. 7). The results obtained for the verification formulation (VF) are presented in table 8 and compared with the predicted values as per the profiler. The numerical immediacy was observed between the predicted and the observed value and indicates validity of the model.

Table 8: Composition of VF and of RTV-SMEDDS

\begin{tabular}{llll}
\hline Formulation & Oleic acid & Labrasol & PEG 6000 \\
\hline VF-ETV-SMEDDS & 0.130 & 0.652 & 0.218 \\
OF-ETV-SMEDDS & 0.117 & 0.659 & 0.224 \\
\hline
\end{tabular}

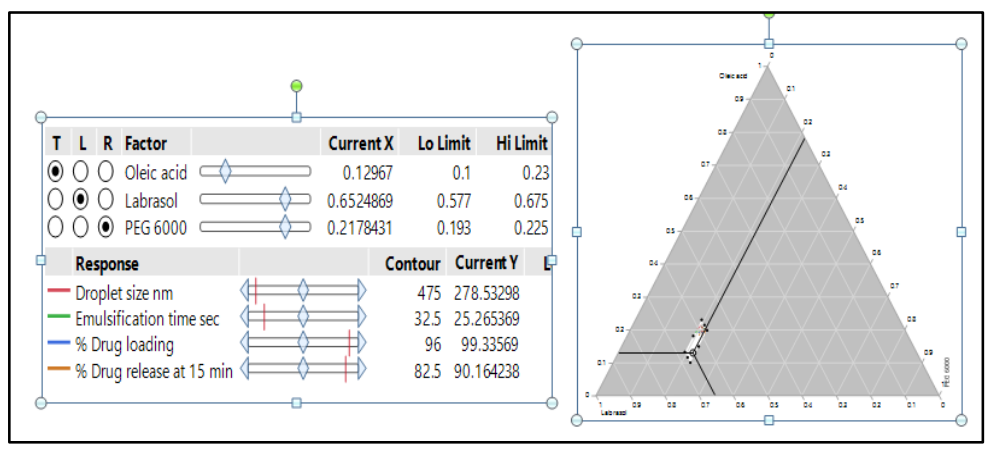

Fig. 7: Mixture profiler report

\section{Optimization of formulation}

The global desirability function obtained through the prediction profiler was utilized for the simultaneous optimization of ETV-SMEDDS. The prediction profiler shows a continuous correlation between multiple factors and multiple responses, giving a complete picture of the variability possible within the selected extreme values. The maximal global desirability value was found to be 0.9415 . The global desirability values indicates that the selected factors and responses have a good correlation and are significant enough for optimization and prediction of best formulation. The predicted values of droplet size, emulsification time, \% drug loading and \% drug release at $15 \mathrm{~min}$ were $252.55 \mathrm{~nm}$, $24.39 \mathrm{sec}, 99.85 \%$ and $91.605 \%$, respectively, at oil, surfactant and cosurfactant of $0.1169,0.6594$ and 0.2236 respectively. The optimized level of factors yielded a formulation with minimal droplet size, faster emulsification process, maximum drug loading with the faster release of drug from the formulation (table 9). The experimental values and predicted values were in close agreement with each other. This showed the efficiency of the optimization process in predicting the quality attributes of ETV-SMEDD. The zeta potential obtained for the optimized formulation indicates the stearic stability of the formulation and the report obtained is presented in the fig. 11.

Hence the studies shows that the development of ETV-SMEDDS by the application of QbD concept could be a desirable approach in attaining the therapeutic and the formulation goals.

Table 9: Predicted and experimental values obtained for VF-ETV-SMEDDS and OF-ETV-SMEDDS

\begin{tabular}{|c|c|c|c|c|c|c|c|c|c|c|c|c|}
\hline \multirow[t]{2}{*}{$\begin{array}{l}\text { Formula } \\
\text { tion }\end{array}$} & \multicolumn{2}{|c|}{ Droplet size (nm) } & \multirow{2}{*}{$\begin{array}{l}\% \\
\text { Differe } \\
\text { nce }\end{array}$} & \multicolumn{2}{|c|}{$\begin{array}{l}\text { Emulsification } \\
\text { time (sec) }\end{array}$} & \multirow{2}{*}{$\begin{array}{l}\% \\
\text { Differe } \\
\text { nce }\end{array}$} & \multicolumn{2}{|c|}{ \% Drug loading } & \multirow{2}{*}{$\begin{array}{l}\% \\
\text { Differe } \\
\text { nce }\end{array}$} & \multicolumn{2}{|c|}{$\begin{array}{l}\text { \% Drug release at } \\
15 \text { min }\end{array}$} & \multirow{2}{*}{$\begin{array}{l}\% \\
\text { Differe } \\
\text { nce }\end{array}$} \\
\hline & $\begin{array}{l}\text { Predic } \\
\text { ted }\end{array}$ & $\begin{array}{l}\text { Experim } \\
\text { ental }\end{array}$ & & $\begin{array}{l}\text { Predic } \\
\text { ted }\end{array}$ & $\begin{array}{l}\text { Experim } \\
\text { ental }\end{array}$ & & $\begin{array}{l}\text { Predic } \\
\text { ted }\end{array}$ & $\begin{array}{l}\text { Experim } \\
\text { ental }\end{array}$ & & $\begin{array}{l}\text { Predic } \\
\text { ted }\end{array}$ & $\begin{array}{l}\text { Experim } \\
\text { ental }\end{array}$ & \\
\hline $\begin{array}{l}\text { VF-ETV- } \\
\text { SMEDDS }\end{array}$ & 278.53 & $\begin{array}{l}286.5 \pm 4.9 \\
2\end{array}$ & 2.86 & 25.26 & $26 \pm 0.58$ & 2.9 & 99.33 & $\begin{array}{l}98.12 \pm 0.8 \\
6\end{array}$ & -1.218 & 90.16 & $91.23 \pm 2.1$ & 1.18 \\
\hline $\begin{array}{l}\text { OF-ETV- } \\
\text { SMEDDS }\end{array}$ & 252.55 & $\begin{array}{l}262.2 \pm 3.5 \\
4\end{array}$ & 3.821 & 24.39 & $24 \pm 1.0$ & -1.59 & 99.85 & $\begin{array}{l}98.45 \pm 0.4 \\
5\end{array}$ & -1.402 & 91.605 & $\begin{array}{l}90.02 \pm 1.8 \\
6\end{array}$ & -0.63 \\
\hline
\end{tabular}

*Data expressed as mean \pm SD $(n=3)$ 

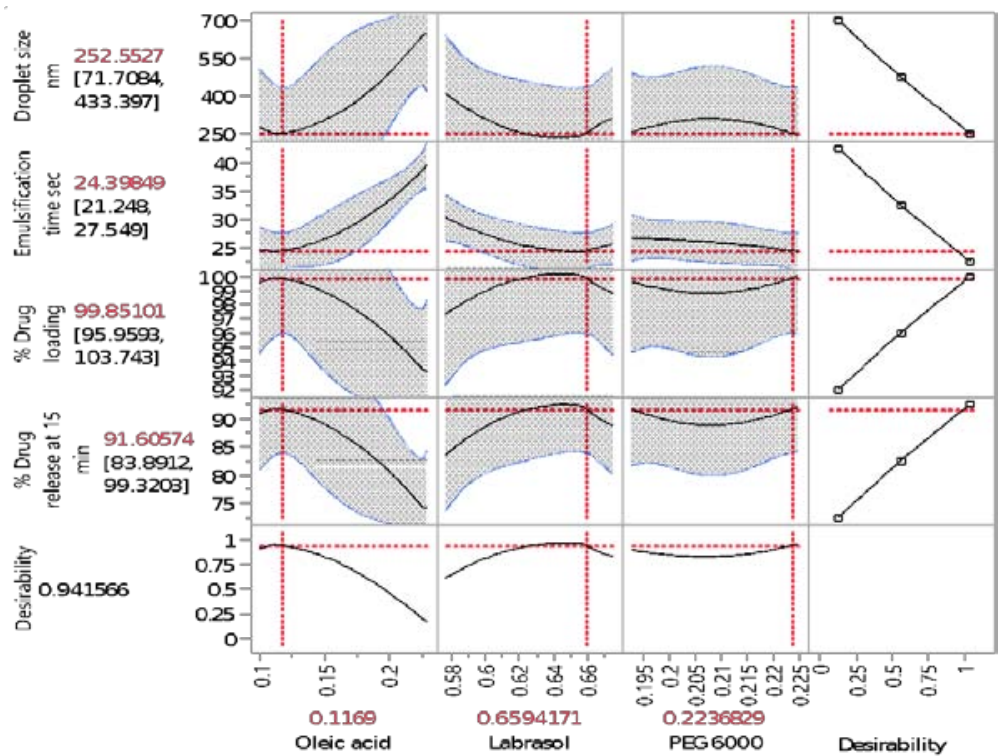

Fig. 8: Prediction profiler

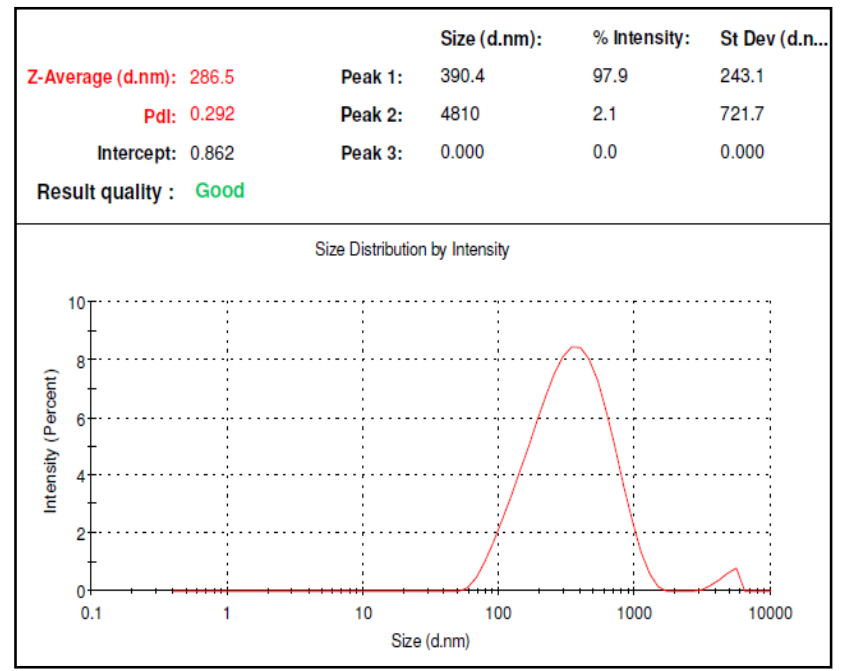

Fig. 9: Droplet size report for VF-ETV-SMEDDS

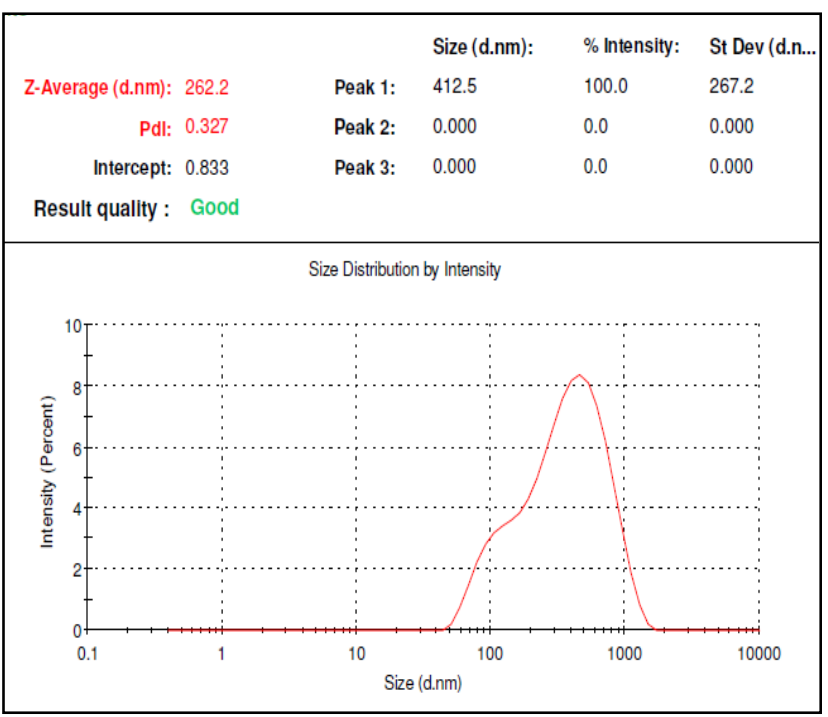

Fig. 10: Droplet size report for OF-ETV-SMEDDS 


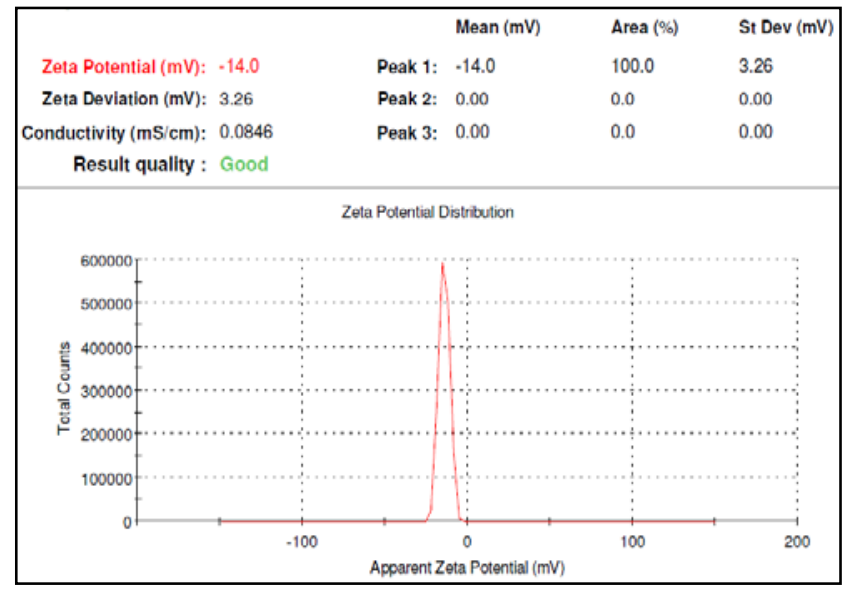

Fig. 11: Zeta potential report for OF-ETV-SMEDDS

\section{CONCLUSION}

SMEDDS were a promising approach for the formulation of poorly water-soluble drugs. The predetermined quality characteristics of ETV-SMEDDS were achieved with the implementation of QbD concepts throughout the development process. The detailed analysis of the three independent variables called oleic acid, labrasol, PEG 6000 and their effects on the quality attributes such as droplet size, emulsification time, drug loading efficiency and \% drug release was studied with the application of statistical mixture design. This study showed the potential of QbD in SMEDDS development

\section{ABBREVIATIONS}

AIDS: Acquired immunodeficiency syndrome, BCS: Biopharmaceutical classification system, CMA: Critical material attributes, CPP: Critical process parameters, DoE: Design of experiment, ETV: Etravirine, HIV: Human immunodeficiency virus, HLB: Hydrophilic lipophilic balance, LBDDS: Lipid-based drug delivery system, OF: Optimized formulation, PDI: Polydispersibility index, PEG: Polyethylene glycol, QbD: Quality by design, QTPP: Quality target product profile, REM: Risk estimation matrix, SEDDS: Self emulsifying drug delivery system, SMEDDS: Self micro emulsifying drug delivery system, VF: Verification formulation.

\section{FUNDING}

Nil

\section{AUTHORS CONTRIBUTIONS}

All the authors have contributed equally.

\section{CONFLICTS OF INTERESTS}

There are no conflicts of interests.

\section{REFERENCES}

1. Jadhav JB, Girawale NN, Chaudhari RA. Quality by design (QBD) approach used in development of pharmaceuticals. Int J Pure Appl Biosci 2014;2:214-3.

2. Lawrence XY, Amidon G, Khan MA, Hoag SW, Polli J, Raju GK, Woodcock J. Understanding pharmaceutical quality by design. AAPS J 2014;16:771-83.

3. Lawrence XY. Pharmaceutical quality by design: product and process development, understanding, and control. Pharm Res 2008;25:781-91.

4. Scholler Gyure M, Kakuda TN, Raoof A, De Smedt G, Hoetelmans RM. Clinical pharmacokinetics and pharmacodynamics of etravirine. Clin Pharmacokinet 2009;48:561-74.

5. Kakuda TN, Schöller Gyüre M, Hoetelmans RM Pharmacokinetic interactions between etravirine and nonantiretroviral drugs. Clin Pharmacokinet 2011;50:25-39.

6. Wang L, Dong J, Chen J, Eastoe J, Li X. Design and optimization of a new self-nano emulsifying drug delivery system. J Colloid Interf Sci 2009;330:443-8.
7. Kassem AM, Ibrahim HM, Samy AM. Development and optimization of atorvastatin calcium loaded selfnanoemulsifying drug delivery system (SNEDDS) for enhancing oral bioavailability: in vitro and in vivo evaluation. J Microencapsul 2017:34:319-33.

8. Nasr AM, Gardouh AR, Ghonaim HM, Ghorab MM. Design, formulation and in vitro characterization of irbesartan solid selfnanoemulsifying drug delivery system (S-SNEDDS) prepared using spray drying technique. J Chem Pharm Res 2016;8:159-83.

9. Beg S, Sandhu PS, Batra RS, Khurana RK, Singh B. QbD-based systematic development of novel optimized solid selfnanoemulsifying drug delivery systems (SNEDDS) of lovastatin with enhanced biopharmaceutical performance. Drug Delivery 201518;22:765-84.

10. Herneisey M, Lambert E, Kachel A, Shychuck E, Drennen JK, Janjic JM. Quality by design approach using multiple linear and logistic regression modeling enables microemulsion scale up. Molecules 2019;24:1-20.

11. Kalamkar R, Wadher S. Design and optimization of novel self nano emulsifying formulation of Etodolac. Int Res J Pharm 2018;9:85-90.

12. Reddy MS, Rambabu B, Vijetha KA. Development and evaluation of solid self nano emulsifying drug delivery system of poorly soluble olmesartan medoxomil by using adsorption on to solid carrier technique. Int J Pharm Sci Res 2018;9:3398-407.

13. Cafaggi S, Leardi R, Parodi B, Caviglioli G, Bignardi G. An example of application of a mixture design with constraints to a pharmaceutical formulation. Chemom Intell Lab Syst 2003;65:139-47.

14. Truong DH, Tran TH, Ramasamy T, Choi JY, Lee HH, Moon C, et al. Development of solid self-emulsifying formulation for improving the oral bioavailability of erlotinib. AAPS PharmSciTech 2016;17:466-73.

15. Saritha D, Bose P, Nagaraju R. Formulation and evaluation of self-emulsifying drug delivery system (SEDDS) of Ibuprofen. Int J Pharm Sci Res 2014;5:3511-9.

16. Sahoo SK, Suresh P, Acharya U. Design and development of selfmicroemulsifying drug delivery systems (SMEDDS) of telmisartan for enhancement of in vitro dissolution and oral bioavailability in rabbit. Int J Appl Pharm 2018;10:117-26.

17. Islambulchilar $\mathrm{Z}$, Valizadeh $\mathrm{H}$, Zakeri Milani P. Systematic development of DoE optimized SNEDDS of sirolimus with enhanced intestinal absorption. J Drug Delivery Sci Technol 2014;24:620-7.

18. Chintalapudi R, Murthy TE, Lakshmi KR, Manohar GG. Formulation, optimization and evaluation of self-emulsifying drug delivery systems of nevirapine. Int J Pharm Investig 2015;5:205-13.

19. Dissolution methods Database. U. S. Food and Drug Administration. Available from: https://www. accessdata.fda.gov/scripts/cder/dissolution/dspsearch result.cfm [Last accessed on 07 Jan 2020]

20. Preethi GB, Shivakumar HN, Ravi Kumar M, Sweta N. Prototype self emulsifying system of etravirine: design, formulation and in vitro evaluation. Int J Appl Pharm 2018;10:13-9. 